\title{
Papilloedema, CSF pressure, and CSF flow in cerebral tumours
}

\author{
H. VA N C R E VEL \\ From the Department of Neurology, Erasmus University, Academisch Ziekenhuis Dijkzigt, \\ Rotterdam, Netherlands
}

SUMMARY The presence or absence of papilloedema and the cisternal CSF pressure were compared with the RIHSA cisternograms in 24 patients with supratentorial tumours. It was found that severe subarachnoid obstruction of CSF flow, leading to impaired CSF absorption at the superior sagittal sinus, was the main cause of raised CSF pressure and papilloedema associated with supratentorial tumours.

Some brain tumours cause papilloedema, others, of ten quite as large, do not. This paper attempts to explain the main cause of that difference.

In large series of patients with cerebral tumours, papilloedema was present in $60 \%$, and in supratentorial tumours in $50 \%$ of cases (Petrohelos and Henderson, 1951; Brégeat, 1956; Huber, 1956; Tönnis, 1959). The presence of papilloedema is highly correlated with raised CSF pressure, and its absence is usually due to absence of sustained elevation of CSF pressure (van Crevel, 1975). Therefore (with some qualifications, see Discussion), to understand the presence or absence of persistently raised CSF pressure is to understand the presence or absence of papilloedema in cerebral tumours.

The approach to this problem has been dominated by the Monro-Kellie doctrine and its later elaborations. It was postulated that brain, blood, and CSF are incompressible and contained within a rigid skull, and that, therefore, all spaceoccupying lesions must lead to raised CSF pressure once the capacity for "compensation" -for example, by expulsion of CSF into the spinal theca-is exhausted (Langfitt, 1972). If this were true for tumours, a high correlation should be found between tumour size and papilloedema. In fact, however, this correlation is low (Brégeat, 1956) or, according to some authors, absent (Tönnis and Krenkel, 1957).

Address for reprint requests : Dr H. van Crevel, Department of Neurology, Academisch Ziekenhuis Dijkzigt, Rotterdam, Netherlands.

Accepted 27 December 1978
It should not be surprising that the MonroKellie doctrine and the implied simple relationship between intracranial volume and CSF pressure do not fit the facts in a slow process like the growth of a tumour. In the first place, given time, brain is compressible-that is, it atrophies, as is obvious from the large indentations produced by meningiomas. So, if brain atrophy should roughly equal tumour growth, the CSF pressure need not rise at all. Furthermore, in the MonroKellie concept, the CSF is regarded as a static component, whereas of course it is produced continually at a rate of some $500 \mathrm{ml} /$ day (Davson, 1967; Milhorat, 1972), and must be absorbed at the same rate if the CSF pressure is to stay normal. Therefore, the following hypothesis could be made. By obstructing CSF flow, a tumour, irrespective of its size, could lead to impaired CSF absorption at the superior sagittal sinus, and so to raised CSF pressure (Fig. 1B); but as long as the quantity of CSF reaching the superior sagittal sinus equals its production, CSF pressure need not necessarily rise (Fig. 1C). This hypothesis is examined in the present study for supratentorial tumours, by comparing the presence or absence of papilloedema, and the CSF pressure, with radioiodinated human serum albumin (RIHSA) cisternograms.

\section{Patients and methods}

Twenty-four patients were studied, 12 with and 12 without papilloedema (Table 1). The size of the tumours was measured in three dimensions 


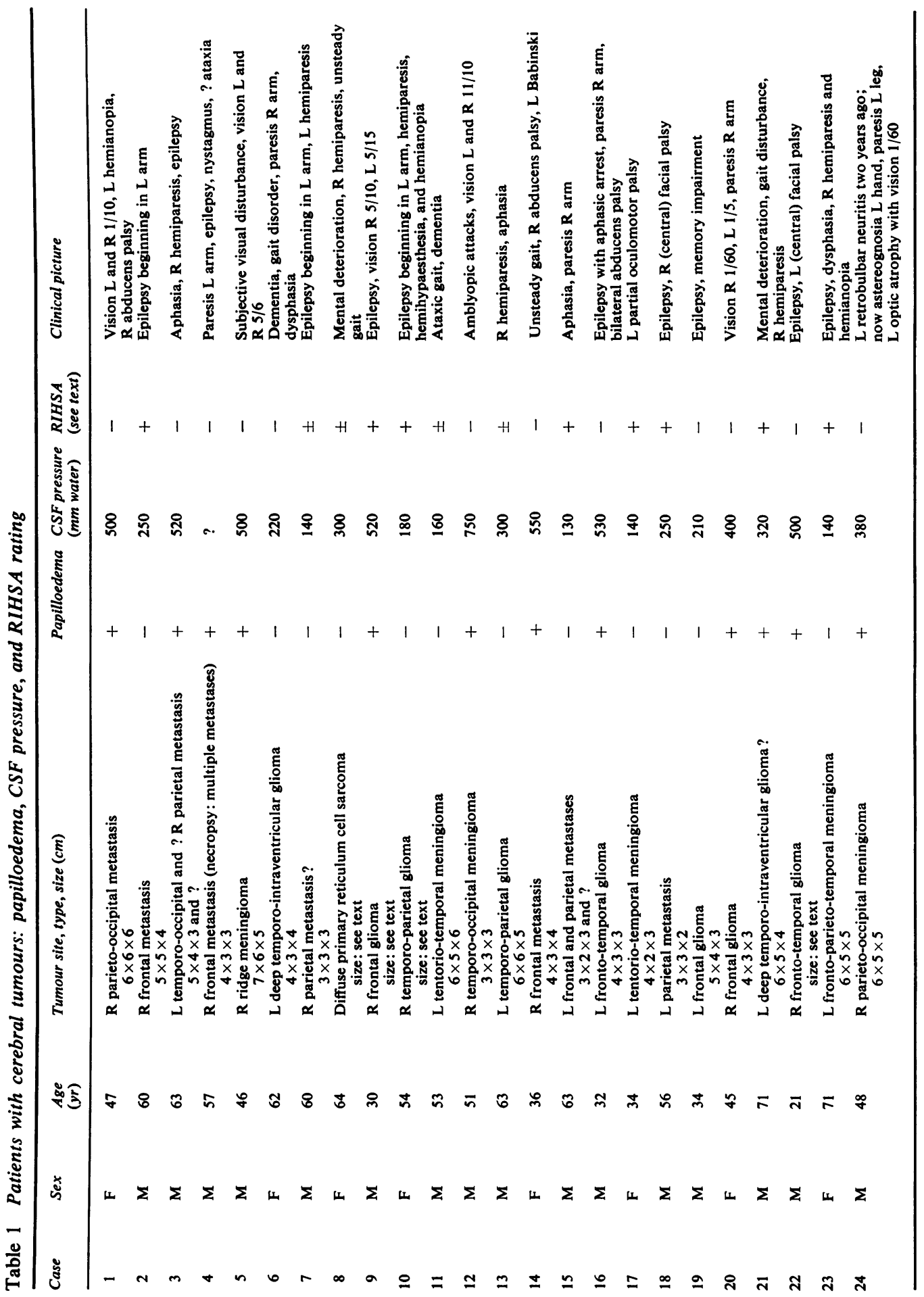




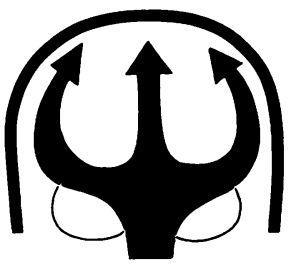

A

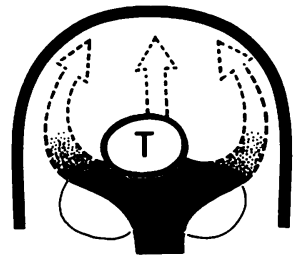

B

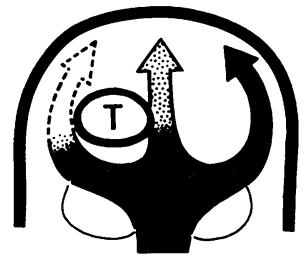

C (sagittal, vertical, and coronal) from the angiography subtraction pictures and the isotope brain scans. This proved possible to approximations of centimetres in 20 cases.

Before CAT equipment became available, we used RIHSA cisternography for some time in the diagnosis of supratentorial tumours, as recommended by Di Chiro (1973). It was done only in clinically stable adult patients. Cisternal puncture was preferred to lumbar puncture as it causes little or no after-leakage of CSF, and so the intracranial dynamics are not upset. Because brain shift is more dangerous than raised CSF pressure in itself (van Crevel, 1972), signs of brainstem compression were regarded as a contraindication, but papilloedema was not. Cisternal puncture was performed with the patient almost supine, the shoulders raised and supported, the neck flexed, and the head resting against a special stand designed for pneumoencephalography (Ziedses des Plantes, 1950). Apart from the puncture, the patients experienced no discomfort, and no complications occurred. The CSF pressure was measured with the shoulder as reference point; in a large number of cases this technique has been shown to produce values roughly equal to those of lumbar puncture in the lateral recumbent position.

Direct techniques are not available for measuring CSF absorption at the superior sagittal sinus in patients. Therefore, the amount of activity along the superior sagittal sinus on the RIHSA cisternograms 24 hours after injection was regarded as an index of the CSF absorption there. This was described on the anterior and lateral 24 hour scans, and rated as: normal or nearly normal, absent or nearly absent, and intermediate $(+,-$, and \pm in Table 1). After completion of the whole study, the rating was repeated without knowledge of the clinical data, with one change as a result. Examples of the three rating grades are shown in Fig. 2.

Plasma RIHSA activity was measured 24 hours after cisternal injection, as an index of total CSF absorption.

\section{Results}

PAPILLOEDEMA AND CSF PRESSURE

Not unexpectedly, the correlation between papilloedema and raised CSF pressure was confirmed (Fig. 3). Six patients without papilloedema had borderline or moderately raised CSF pressure, with a maximum of $300 \mathrm{~mm}$ water. Normal lumbar CSF pressure may range between 40 and $250 \mathrm{~mm}$ water (Gilland et al., 1974). All patients with papilloedema had a CSF pressure above $300 \mathrm{~mm}$ water.

\section{PAPILlOEDEMA AND CSF FLOW}

The main result of this study is shown in Table 2 .

The correlation between the presence of papilloedema and the reduction of RIHSA activity along the superior sagittal sinus at 24 hours is statistically significant $(P<0.01$, YatesCochran test). This supports the hypothesis that papilloedema in supratentorial tumours is mainly caused by severe obstruction of CSF flow, resulting in impaired absorption of CSF at the superior sagittal sinus.

The two patient groups are compared further in Table 3. The age difference of more than 10 years is probably not fortuitous and will be discussed below. The type of tumour was not different for the two groups. Tumour size could be measured in 20 cases only, 10 in both groups. Though the mean size in the papilloedema group was slightly greater, the difference is not statistically significant, neither in each dimension

Table 2 Relationship between papilloedema and the amount of RIHSA activity along the superior sagittal sinus 24 hours after injection

\begin{tabular}{llll}
\hline & $\begin{array}{l}\text { Normal } \\
\text { or nearly } \\
\text { normal }\end{array}$ & $\begin{array}{l}\text { Intermediate } \\
\text { Absent } \\
\text { or nearly } \\
\text { absent }\end{array}$ \\
\hline $\begin{array}{l}\text { Patients with } \\
\text { papilloedema }(\mathrm{n}=12)\end{array}$ & 2 & 0 & 10 \\
$\begin{array}{l}\text { Patients without } \\
\text { papilloedema }(\mathrm{n}=12)\end{array}$ & 6 & 4 & 2 \\
\hline
\end{tabular}



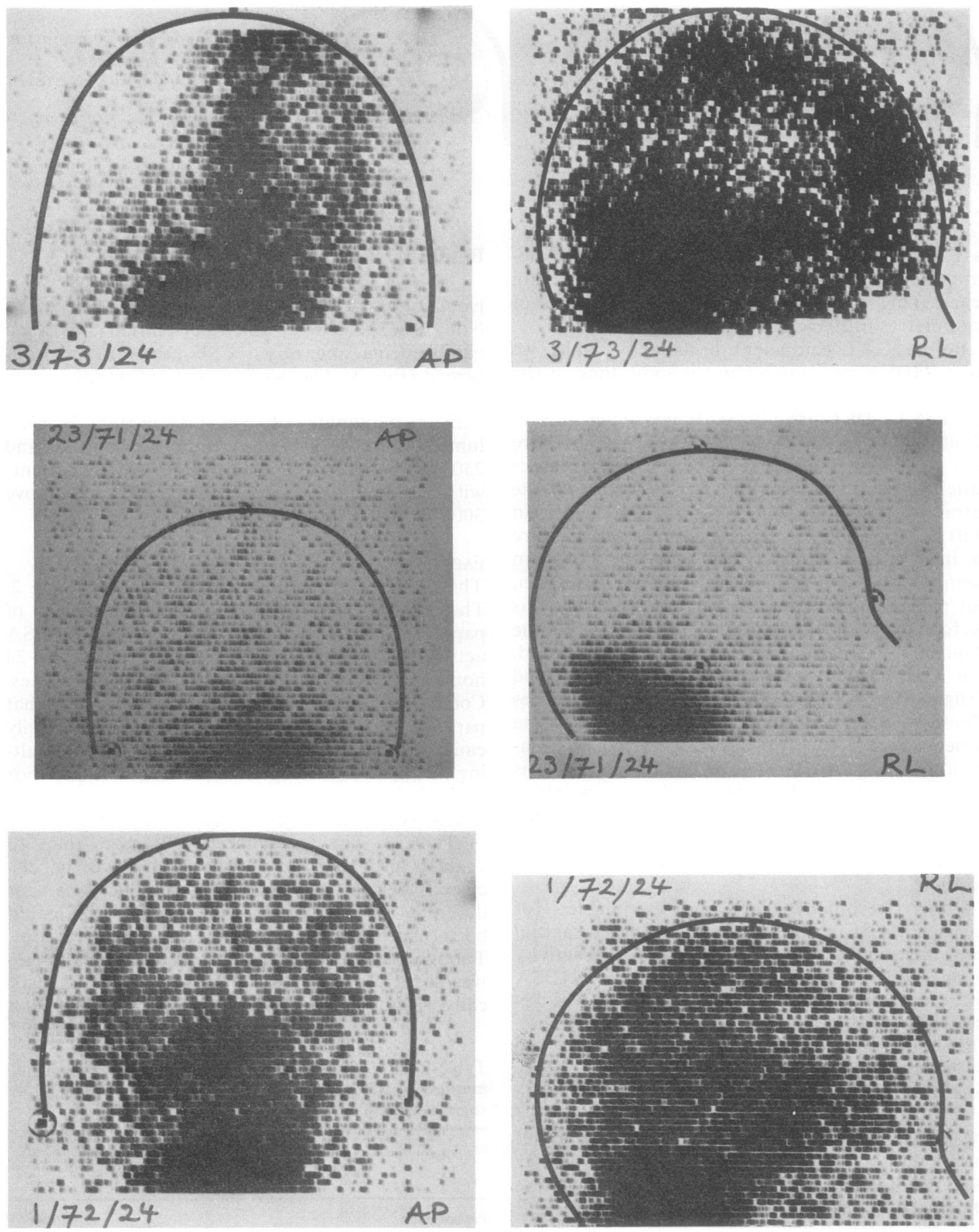

Fig. 2 Rating grades of RIHSA activity along the superior sagittal sinus; anterior and right lateral $24 \mathrm{hr}$ scans. $A=$ normal or nearly normal (case 10). B=absent or nearly absent (case 6). $C=$ intermediate (case 8 ). 


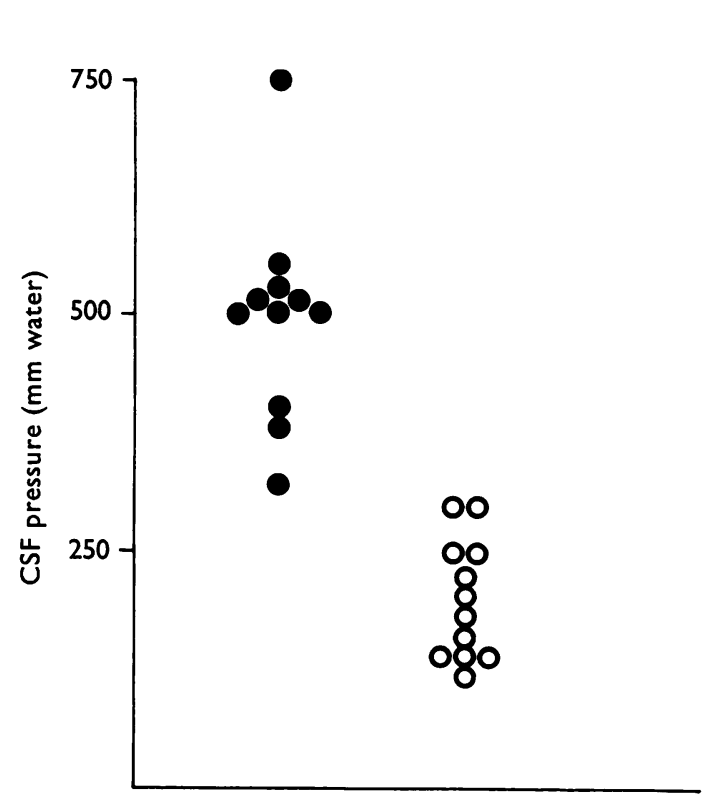

Fig. 3 Relationship between cisternal CSF pressure and the presence (O) or absence $(O)$ of papilloedema. CSF pressure measurement was omitted in case 4.

Table 3 Comparison of patients with and without papilloedema

\begin{tabular}{lll}
\hline & $\begin{array}{l}\text { Patients with } \\
\text { papilloedema } \\
(n=12)\end{array}$ & $\begin{array}{l}\text { Patients without } \\
\text { papilloedema } \\
(n=12)\end{array}$ \\
\hline Mean age & $\begin{array}{l}45.6 \text { years } \\
\text { Metastases (4) } \\
\text { Gliomas (5) } \\
\text { Meningiomas (3) }\end{array}$ & $\begin{array}{l}\text { Getastases (4) } \\
\text { Sliomas (4) } \\
\text { Meningiomas (3) } \\
45 \times 38 \times 38 \mathrm{~mm}\end{array}$ \\
\hline
\end{tabular}

separately nor in the three combined $(P>0.20$, Wilcoxon's two-sample test). As to the remaining four tumours, the two from the group without papilloedema (cases 8 and 10) were, if anything, larger than the two from the papilloedema group (cases 9 and 22) as judged from the surgical and pathological notes. The site of the tumours was similar in both groups; only parietal lobe tumours were less common in the papilloedema group.

Finally, the 24 hour plasma RIHSA activity yielded values of very wide range, and will not be reported here in detail. However, the mean values for the groups with and without papilloedema were almost exactly equal.

\section{Discussion}

CSF OBSTRUCTION AS THE MAIN CAUSE OF PAPILLOEDEMA IN SUPRATENTORIAL TUMOURS

The results are compatible with the hypothesis that papilloedema in supratentorial tumours is due mainly to obstruction of subarachnoid CSF flow, leading to impaired CSF absorption at the superior sagittal sinus and so to raised CSF pressure. The classic observations of Lundberg (1960) have revealed that in patients with cerebral tumours, the CSF pressure, continuously recorded, is subject to marked fluctuation. Our CSF pressure values represent single measurements made at chance moments. Nevertheless, they correlated surprisingly well to the absence or presence of papilloedema. Therefore the division into a "papilloedema" and a "no papilloedema" group, the former with higher CSF pressure than the latter, seems justified.

The idea that, in cerebral tumours, obstruction of CSF flow causes raised CSF pressure is of course not new, but has usually been applied only to intraventricular obstruction, and has not been investigated for subarachnoid CSF flow. This idea rests on the traditional concept of the CSF being secreted mainly within the ventricles, and drained mainly through the arachnoid villi and granulations into the superior sagittal sinus. This concept is still regarded as essentially correct, even though ventricular CSF production may be decreased with high CSF pressure (Milhorat, 1972; Pollay, 1977).

Continuation of CSF production with cessation or severe impairment of CSF absorption in the superior sagittal sinus necessitates absorption by subsidiary routes. Such routes-for example, the basal sinuses and the spinal arachnoid villi-are known to exist, though their importance under normal circumstances is uncertain (Millen and Woollam, 1962; Davson, 1967; Kido et al., 1976). Another possibility, in cases with hydrocephalus, is ventricular reabsorption (Milhorat, 1972; James et al., 1975). Absorption of CSF by nonphysiological routes in brain tumours has been established by the isotope studies of Paraicz et al. (1972), and is confirmed by our mean plasma RIHSA values being equal in the two groups. Our findings indicate that the superior sagittal sinus is only replaced by other CSF absorption routes if the CSF pressure is raised (with possible exceptions, see below).

DEFECTS OF THE CONCEPT OF CSF OBSTRUCTION Although the concept of CSF obstruction proposed in this paper may be valid, it is too simplistic and four cases were inconsistent with it. 
Two patients (cases 6 and 19) had no papilloedema though RIHSA was virtually absent along the superior sagittal sinus. The CSF pressure was only 220 and $210 \mathrm{~mm}$ respectively, so this inconsistency cannot be explained by a time lag between the rise of CSF pressure and the development of papilloedema. Possibly, normal CSF pressure, in spite of superior sagittal sinus inaccessibility, is the result of absorption of CSF by subsidiary routes at normal CSF pressure, known to exist in some conditions. For example, in "normal" pressure hydrocephalus (with total inaccessibility of the superior sagittal sinus) sustained elevation of CSF pressure and papilloedema are absent, though transient rises in CSF pressure have been recorded (Symon et al., 1972). In experimental communicating hydrocephalus the CSF pressure is increased initially, but later falls into the normal range (James et al., 1975). Hydrocephalus was present in case 6; in case 19 air studies were not done.

Two other patients (cases 9 and 21) did have papilloedema (CSF pressure 520 and $320 \mathrm{~mm}$ respectively), and yet "enough" RIHSA along the superior sagittal sinus. In this context, it should be remembered that CSF absorption through the arachnoid villi can be functionally impaired, while the subarachnoid CSF channels are anatomically patent. For example, in "benign intracranial hypertension" the CSF infusion test indicates impaired CSF absorption (Martins, 1973), but RIHSA cisternography is normal (James et al., 1974). Raised CSF pressure without obstruction of CSF pathways is also found in other conditions-for example, raised venous pressure or high CSF protein content. Case 21 had a CSF protein of $4.65 \mathrm{~g} / 1$; case 9 remains unexplained.

These speculations are mentioned in view of further investigation, and to stress that RIHSA cisternography is not a direct index of CSF absorption at the superior sagittal sinus.

\section{FACTORS DETERMINING THE OCCURRENCE OF}

PAPILLOEDEMA IN CEREBRAL TUMOURS

In cerebral tumours, raised CSF pressure is necessary but not sufficient for the development of papilloedema (Table 4). Raised CSF pressure must not only be present for a certain period of time, but the optic nerve sheaths must also be patent, as shown experimentally (Hayreh, 1968). Unilateral or bilateral absence of papilloedema in cerebral tumours with raised CSF pressure may thus be caused by compression of the optic nerve sheath(s) by the tumour (Levatin, 1957), or by congenital occlusion of the sheath(s) (Walsh and
Table 4 Absence of papilloedema in cerebral tumours

\begin{tabular}{ll}
\hline Rarely & In most cases \\
\hline CSF pressure is raised, but & CSF pressure is not \\
papilloedema is absent & persistently raised, usually \\
(*unilaterally or bilaterally) & because CSF flow to the \\
because of: & superior sagittal sinus is \\
Time factor & not severely obstructed. \\
Optic nerve sheath occlusion* & This depends on: \\
Glaucoma*, myopia* & Age of patient \\
Optic atrophy* & Site of tumour \\
& Size of tumour \\
& Oedema, hydrocephalus \\
\hline
\end{tabular}

Hoyt, 1969). Further, glaucoma (Brégeat, 1956) and severe myopia (Huber, 1956) can account for unilateral or bilateral absence of papilloedema. Optic atrophy also prevents papilloedema, as is well known from the Foster-Kennedy syndrome. In our series, one patient (case 24) had unilateral papilloedema, which was explained by antecedent optic atrophy in the other eye. Otherwise there was a good correlation between raised CSF pressure and papilloedema. Absence of papilloedema in cerebral tumours is usually due to absence of persistently raised CSF pressure. The factors which determine the CSF pressure in cerebral tumours will now be discussed, in relation to CSF obstruction.

Papilloedema and raised CSF pressure are less frequent in old age (Moersch et al., 1941; Kloss, 1952). This is usually explained by pre-existent brain atrophy, more space being available for the tumour. In the concept of CSF obstruction, more subarachnoid space would mean a smaller chance of CSF block. Whatever its explanation, the influence of age was confirmed in our series (Table 3).

There was no significant difference in tumour type between our two groups (Table 3 ). In large series, no consistent relationship between tumour type and incidence of papilloedema has been established either: Brégeat (1956) saw papilloedema more often in malignant, Huber (1956) in benign tumours, and the results of Tönnis (1959) were equivocal. Apparently, rapid growth of a tumour does not lead more often to CSF blocks than slow growth.

It would be surprising if the size of brain tumours had no influence at all on the incidence of papilloedema, but the correlation is low. In our two groups there was no statistically significant difference (Table 3); but the amount of brain shift (also dependent upon infiltrative versus expanding growth, oedema, and hydrocephalus) could not be measured, as no CAT scan was yet 
available. However, in view of our findings the total extra volume would be effective by obstruction of CSF flow rather than by "spaceoccupation" in itself. Papilloedema may even increase (and the CSF pressure may remain high) after removal of a tumour (Paton, 1905; Bynke and Österlin, 1960). Again, this may be due to postoperative CSF blocks, as we could demonstrate by postoperative RIHSA cisternography in one patient (case 12).

The site of a tumour relative to the CSF pathways must be important with regard to papilloedema. In large series, papilloedema was more frequent in frontal and temporal than in parietal lobe tumours (Brégeat, 1956; Huber, 1956; Tönnis and Krenkel, 1957), and in our small series this is also apparent (Table 1). This may be due to the greater distance of parietal lobe tumours from the "strategic" CSF flow point-that is, the basal cisterns leading to the Sylvian fissures and the interhemispheric fissure. The high frequency of papilloedema in infratentorial, especially cerebellar, tumours is well known, but not self-evident. In current textbooks, it is usually attributed to the concomitant obstructive hydrocephalus (for example, Merritt, 1973). Again, it is conceivable that this hydrocephalus causes increased CSF pressure by blocking the upward passage of CSF in the subarachnoid spaces at the tentorial hiatus, and not by simple "space-occupation." This was suggested long ago by Cairns (1939), and demonstrated for hydrocephalus without tumour by RIHSA cisternography before and after a shunt by Milhorat (1972). However, posterior fossa tumours may sometimes produce papilloedema but no hydrocephalus, and vice versa. This merits further investigation.

\section{PAPILlOedeMa AS A CLINICAL SIGN}

In patients with brain tumours, papilloedema signifies that the CSF pressure has been raised for some time, usually because the CSF flow to the superior sagittal sinus is severely obstructed. Papilloedema gives no indication of the type of tumour, and very little of its size. Moreover, the relationship between the CSF pressure and the clinical state of the patient is erratic, as shown by continuous CSF pressure recording (Jennett and Johnston, 1972).

Absence of papilloedema, if not caused by ophthalmological factors or time lag, merely means that the CSF pressure is not raised persistently, usually because CSF flow to the superior sagittal sinus is not severely obstructed. That, in itself, does not exclude extensive brain shifts or even brain herniation (Lundberg, 1960).
As Miller and Adams (1972) have stressed, it is of vital importance not to equate raised CSF pressure with brain shift. Papilloedema is a reliable sign of raised CSF pressure, but neither papilloedema nor its absence are a clue to the presence, extent, or absence of brain shifts.

I am indebted to the late Professor J. W. G. ter Braak who awakened my interest in CSF pressure. Dr P. Crezée, neuroradiologist, performed the cisternal injections, $\mathrm{Mr} \mathbf{R}$. van Strik gave statistical advice, Dr J. van Gijn and Dr L. de Vries made helpful comments, and Mrs C. Thooft-Schlemper prepared the manuscript.

\section{References}

Brégeat, P. (1956). L'oedème papillaire, pp. 544-545 and p. 565. Masson: Paris.

Bynke, H., and Österlin, S. (1960). Temporär progress av staspapiller efter hjärnoperationer. Nordisk Medicin, 63, 824.

Cairns, H. (1939). Raised intracranial pressure: hydrocephalic and vascular factors. British Journal of Surgery, 27, 275-294.

Crevel, H. van (1972). Intracranial CSF pressure and "brain pressure". Psychiatria, Neurologia, Neurochirurgia (Amsterdam), 75, 9-11.

Crevel, H. van (1975). Absence of papilloedema in cerebral tumours. Journal of Neurology, Neurosurgery, and Psychiatry, 38, 931-933.

Davson, H. (1967). Physiology of the Cerebrospinal Fluid, pp. 21-32 and p. 125. Churchill: London.

Di Chiro, G. (1973). Cisternography: from early tribulations to a useful diagnostic procedure. Johns Hopkins Medical Journal, 133, 1-15.

Gilland, O., Tourtellotte, W. W., O'Tauma, L., and Henderson, W. G. (1974). Normal cerebrospinal fluid pressure. Journal of Neurosurgery, 40, 587-593.

Hayreh, S. S. (1968). Pathogenesis of oedema of the optic disc. Documenta Ophthalmologica, 24, 289411.

Huber, A. (1956). Augensymptome bei Hirntumoren, pp. 109-166. Huber: Bern.

James, A. E., Harbert, J. C., Hoffer, P. B., and DeLand, F. H. (1974). CSF imaging in benign intracranial hypertension. Journal of Neurology, Neurosurgery, and Psychiatry, 37, 1053-1058.

James, A. E., Burns, B., Flor, W. F., Strecker, E. P., Merz, T., Bush, M., and Price, D. L. (1975). Pathophysiology of chronic communicating hydrocephalus in dogs (Canis familiaris). Journal of the Neurological Sciences, 24, 151-178.

Jennett, B., and Johnston, I. H. (1972). The uses of intracranial pressure monitoring in clinical management. In Intracranial Pressure I, pp. 353-356. Edited by M. Brock and H. Dietz. Springer: Berlin.

Kido, D. K., Gomez, D. G., Pavese, A. M., and Potts, D. G. (1976). Human spinal arachnoid villi and granulations. Neuroradiology, 11, 221-228. 
Kloss, K. (1952). Hirntumoren höherer Altersstufen. Acta Neurochirurgica, 2, 217-232.

Langfitt, T. W. (1972). Pathophysiology of increased ICP. In Intracranial Pressure I, pp. 361-364. Edited by $M$. Brock and H. Dietz. Springer: Berlin.

Levatin, P. (1957). Increased intracranial pressure without papilledema. Archives of Ophthalmology, $58,683-688$.

Lundberg, N. (1960). Continuous recording and control of ventricular fluid pressure in neurosurgical practice. Acta Psychiatrica et Neurologica Scandinavica, 36, suppl. 149.

Martins, A. N. (1973). Resistance to drainage of cerebrospinal fluid: clinical measurement and significance. Journal of Neurology, Neurosurgery, and Psychiatry, 36, 313-318.

Merritt, H. H. (1973). A Textbook of Neurology, fifth edition, p. 220. Lea and Febiger: Philadelphia.

Milhorat, T. H. (1972). Hydrocephalus and the Cerebrospinal Fluid, pp. 1-41, 135-136, and 137-139. Williams and Wilkins: Baltimore.

Millen, J. W., and Woollam, D. H. M. (1962). The Anatomy of the Cerebrospinal Fluid, pp. 103-122. Oxford University Press: London.

Miller, J. D., and Adams, H. (1972). Physiopathology and management of increased intracranial pressure. In Scientific Foundations of Neurology, pp. 308324. Edited by M. Critchley, J. L. O'Leary, and B. Jennett. Heinemann: London.

Moersch, F. P., Graig, W. McK., and Kernohan, J. W. (1941). Tumors of the brain in aged persons. Archives of Neurology and Psychiatry (Chicago), 45, 235-245.
Paraicz, E., Simkovics, M., and Kutas, V. (1972) Some peculiarities of the passage and absorption in the subarachnoid space at increased ICP investigated by radioisotope methods. In Intracranial Pressure I, pp. 33-36. Edited by M. Brock and $\mathrm{H}$. Dietz. Springer: Berlin.

Paton, L. (1905). Optic neuritis in cerebral tumours and its subsidence after operation. Transactions of the Ophthalmological Society of the United Kingdom, 25, 129-162.

Petrohelos, M. A., and Henderson, J. W. (1951). The ocular findings of intracranial tumor, a study of 358 cases. American Journal of Ophthalmology, 34, 1387-1394.

Pollay, M. (1977). Review of spinal fluid physiology: production and absorption in relation to pressure. Clinical Neurosurgery, 24, 254-269.

Symon, L., Dorsch, N. W. C., and Stephens, R. J. (1972). Pressure waves in so-called low-pressure hydrocephalus. Lancet, 2, 1291-1292.

Tönnis, W. (1959). Die sog. "klassischen" Symptome der intrakraniellen Drucksteigerung; Stauungspapille. In Handbuch der Neurochirurgie, pp. 322 and 326. Edited by $\mathbf{H}$. Olivecrona and W. Tönnis. Springer: Berlin.

Tönnis, W., and Krenkel, W. (1957). Grosshirngeschwülste ohne Stauungspapille. Neurochirurgica, 5, 458-487.

Walsh, F. B., and Hoyt, W. F. (1969). Clinical Neuro ophthalmology, third edition, p. 573. Williams andô Wilkins: Baltimore.

Ziedses des Plantes, B. G. (1950). A special device for encephalography. Acta Radiologica (Stockholm) 34, 408-410. 